\title{
THE
}

\section{Using the Inverted Echo Sounder to Measure Vertical Profiles of Gulf Stream Temperature and Geostrophic Velocity}

\author{
Robert S. Pickart \\ University of Rhode Island \\ D. Randolph Watts \\ University of Rhode Island, randywatts@uri.edu
}

Follow this and additional works at: https://digitalcommons.uri.edu/gsofacpubs

\author{
Citation/Publisher Attribution \\ Pickart, R. S., \& Watts, D. R. (1989). Using the Inverted Echo Sounder to Measure Vertical Profiles of Gulf \\ Stream Temperature and Geostrophic Velocity. J. Atmos. Oceanic Technol., 7(1), 146-156. doi: 10.1175/ \\ 1520-0426(1990)0072.0.CO;2 \\ Available at: https://doi.org/10.1175/1520-0426(1990)007<0146:UTIEST>2.0.C0;2
}

This Article is brought to you for free and open access by the Graduate School of Oceanography at DigitalCommons@URI. It has been accepted for inclusion in Graduate School of Oceanography Faculty Publications by an authorized administrator of DigitalCommons@URI. For more information, please contact digitalcommons@etal.uri.edu. 


\title{
Using the Inverted Echo Sounder to Measure Vertical Profiles of Gulf Stream Temperature and Geostrophic Velocity
}

\author{
ROBERT S. PICKART AND D. RANDOLPH WATTS \\ Graduate School of Oceanography, University of Rhode Island, Narragansett, Rhode Island
}

(Manuscript received 14 December 1988, in final form 31 July 1989)

\begin{abstract}
The methodology for converting the travel time measurement of the inverted echo sounder (IES) into an amplitude of the first baroclinic dynamical mode, $A_{1}$, is presented. For a Gulf Stream IES record the sogenerated $A_{1}(t)$ time series is used to compute a vertical profile of first mode temperature versus time by perturbing a basic state temperature profile. The basic state is constructed by averaging together historical CTD data collected near the IES site. Similarly the first mode amplitudes are used to perturb a basic state dynamic height profile, and, using neighboring IESs, a profile of alongstream geostrophic velocity is obtained at the same location. The resulting IES-derived temperatures and velocities compare favorably to independent current meter results, exhibiting most of the variability observed in both the current meter temperature and alongstream velocity.
\end{abstract}

\section{Introduction}

Since their introduction about fifteen years ago, inverted echo sounders (IESs) have been used extensively in measuring variability in the ocean. The IES is a relatively inexpensive instrument which sits on the ocean floor and periodically measures the round trip time, $\tau$, for a sound pulse to travel to the surface and back. This measurement has been interpreted a number of ways, depending on the geographical location of a given experiment.

Watts and Rossby (1977) showed formally that the travel time $\tau$ is roughly proportional to the change in dynamic height, $\Delta D$, across the main thermocline for regions characterized by a tight $T-S$ relation. Measuring $\Delta D$ has been a common use of the IES, particularly near the equator (e.g., Miller et al. 1985; Chiswell et al. 1986; Katz 1987). In the Gulf Stream IESs have been used to measure the depth of the main thermocline [in particular, the depth of a given isotherm, e.g., Watts et al. (1989)] and also the lateral displacement of Gulf Stream meanders (e.g., Watts and Johns 1982). IESs have also been used similarly at midlatitudes in the South Atlantic (e.g., Garzoli and Bianchi 1987).

In the above applications an empirical (linear) relationship has been established relating changes in $\tau$ to changes in the derived variable (say $\Delta D$ ) using historical data. Then for each particular IES deployment a calibration is necessary to obtain an absolute $\Delta D$

Corresponding author address: Dr. Robert S. Pickart, Graduate School of Oceanography, The University of Rhode Island, Narragansett Bay Campus, Narragansett, RI 02882-1197. (using some type of in situ data such as a CTD or XBT profile). Chiswell et al. (1986) discuss the errors involved in establishing such an empirical formula, including the problem of geographical variation.

At midlatitudes the IES measurement is most sensitive to the lowest baroclinic mode of variability (Watts and Rossby 1977). This can be understood by considering the vertical displacement of isotherms corresponding to the different vertical modes of a stratified ocean. For a first baroclinic mode disturbance, the isotherms throughout the water column rise and fall together, the greatest deflection occurring in the main thermocline. For a second mode disturbance, the warmer isotherms rise (deepen) while the colder isotherms deepen (rise); in the main thermocline, however, displacements are small since this is near the location of the mode's zero crossing. Thus in the former case when the. water column is uniformly warmer (weighted by large temperature changes in the thermocline), this increases the sound speed and decreases $\tau$. In the latter case, however, the sound speed is faster in only part of the water column and slower in the remaining part, so $r$ is hardly changed (temperature perturbations in the thermocline are small and have little effect). This type of cancelling occurs for the higher vertical modes as well.

In the equatorial region the situation is quite different in that the greatest stratification (largest buoyancy frequency) occurs in relatively shallow water. In this case the maximum displacement of the first baroclinic mode occurs below the main thermocline, so the large temperature weighting that occurs at midlatitudes for mode 1 is not as prevalent here. Rather, the upper lobe of 
the second baroclinic mode coincides with the main thermocline giving increased weight to these shallow perturbations; this in turn reduces the cancellation that occurs for mode 2 due to the mode's change in sign. Watts and Rossby (1977) showed that at midlatitudes the IES travel time is roughly 50 times more sensitive to a first mode disturbance than to a second mode disturbance. In contrast, Garzoli and Katz (1981) showed that near the equator $\tau$ is only about three times more sensitive to mode 1 than to mode 2 . Thus an ambiguity exists in interpreting $\tau$ as a modal amplitude in the equatorial region, but not at midlatitudes.

In this work we present the methodology for converting the travel time measurement of the IES into a measurement of the time dependent amplitude of the first baroclinic mode in the Gulf Stream, for the purpose of generating temperature and geostrophic velocity profiles. The methodology is only feasible for those areas of the Gulf Stream characterized by small meandering. The technique involves devising an appropriate basic state profile of temperature, density, etc., for the desired location and computing the corresponding vertical mode shape. Formulated as such, no empirical relationship is constructed for $\tau$, and therefore it is unnecessary to assume an exact linear relationship between $\tau$ and the derived variable. In addition, any geographical variation in this relationship is accurately reflected in our conversion to first mode amplitude. The travel time records which we use come from three closely spaced IESs deployed for three months in the Gulf Stream near Cape Hatteras, from December 1986 to March 1987 (Fig. 1). The calibration necessary for each instrument can be done using XBT profiles taken at the instrument sites.

Once the baroclinic mode amplitude is determined, this, in conjunction with the previously determined mode shape, is used to perturb the basic state temperature profile to generate a time varying vertical profile of temperature. The central IES site also contained a current meter (CM) mooring with instruments at $400 \mathrm{~m}, 700 \mathrm{~m}$, and $1000 \mathrm{~m}$. The temperature time series at these depths from the IES profile compare quite favorably to the independent current meter results. Using all three IESs, a time varying profile of relative geostrophic velocity is also computed at the mooring site using the dynamic method. When the current meter mean velocities are used to determine a reference velocity, the resulting IES-derived geostrophic velocities agree nicely with the measured current meter velocities. This result supports the claim by Watts and Rossby (1977) that the IES can be used to determine geostrophic shear in an appropriate application, as they demonstrated for the MODE region.

\section{Formulation}

We are interested in using the IES to measure variability in the Gulf Stream, which we idealize as per-

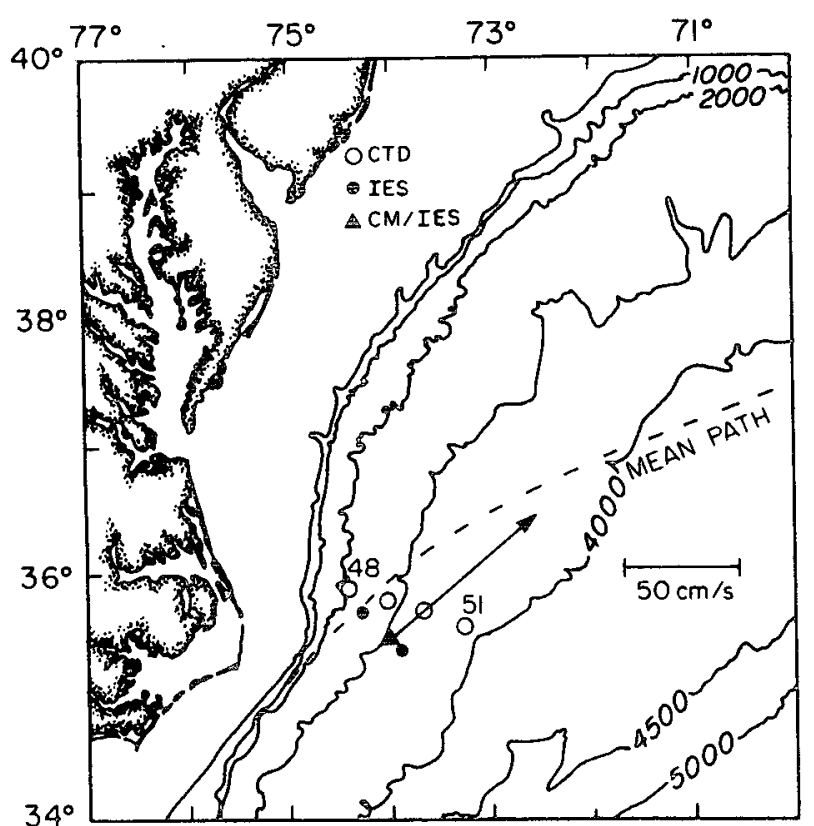

FIG. 1. Positions of the three IESs and CM mooring from the SYNOP pilot study, and CTD stations from Endeavor cruise 88 . The moored instruments were deployed from December 1986-March 1987 , and the CTD section was occupied in August 1982. The average $\mathrm{CM}$ velocity vector at $370 \mathrm{~m}$ is shown. The dashed line is the historical mean location of the Gulf Stream north wall.

turbations upon a basic state profile which varies only in the vertical direction:

$$
T(x, y, z, t)=T_{0}\left[z+z^{\prime}(x, y, z, t)\right],
$$

where $T(x, y, z, t)$ is the perturbed quantity (say temperature $), T_{0}(z)$ is the basic state profile, and $z^{\prime}(x, y$, $z, t)$ is the vertical displacement of the perturbation. The vertical displacement can be expressed as an infinite sum of vertical (linear, flat bottom) modes,

$$
z^{\prime}(x, y, z, t)=\sum_{i} A_{i}(x, y, t) \chi_{i}(z),
$$

where $\chi_{i}(z)$ satisfies the vertical structure equation

$$
\epsilon \chi_{z z}(z)+N(z)^{2} \chi(z)=0,
$$

where $\chi(z)=0$ at the top and bottom boundaries (and $\epsilon$ is the separation constant). While the linear, flat bottom assumptions are not strictly valid for the Gulf Stream, the mode simplification appears to be adequate in this context [Rossby (1987) found this to be true as well for a modal analysis of Gulf Stream energetics ]. From a single mooring in the Gulf Stream near $68^{\circ} \mathrm{W}$, Hall (1986a) derived time series of vertical velocity $(w)$ and showed that the dominant vertical structure is a first baroclinic mode (with additional weak bottom velocities arising from the bottom slope). Hall (1986b) subsequently presented two different scenarios in which $w$ can be understood by considering the cross-stream movement of the Gulf Stream thermal front. It was 
shown that both a baroclinic and barotropic mode were possible, but that the former applied to the data.

In order to empirically determine the vertical structure of $z^{\prime}$ most appropriate for the idealization expressed by (1), we did the following calculation using the CM temperature data from the Cape Hatteras mooring. At each instrument depth we computed the vertical displacement $\hat{\chi}(t)$ such that

$$
T_{\mathrm{cm}}(t)=\overline{T_{\mathrm{cm}}}+\left(\frac{d}{d z} T_{0}\right) \hat{\chi}(t)
$$

where $T_{\mathrm{cm}}(t)$ is the CM temperature, $\overline{T_{\mathrm{cm}}}$ is the record long mean, and $d T_{0} / d z$ is the vertical temperature gradient determined from nearby CTD data. The quantity $\hat{\chi}(t)$ is the displacement required to produce the observed $\mathrm{CM}$ temperatures using the mean temperature as a reference. The resulting vertical structure of $\bar{\chi}(t)$ has a first baroclinic mode character; Fig. 2 shows the first empirical orthogonal function (EOF) mode of $\hat{\chi}(t)$ in relation to the first baroclinic dynamical mode determined from (3) using the local $N(z)$ profile. Also shown is the first EOF mode vertical structure of $w$ at $68^{\circ} \mathrm{W}$ from Hall (1986a). The conclusion to be made from Fig. 2 is that the linear, flat bottom dynamical mode shape is consistent with that determined empirically in the region spanning the main thermocline.

We therefore make the important assumption (which we further justify later) that the Gulf Stream variability being studied is predominantly first baro-

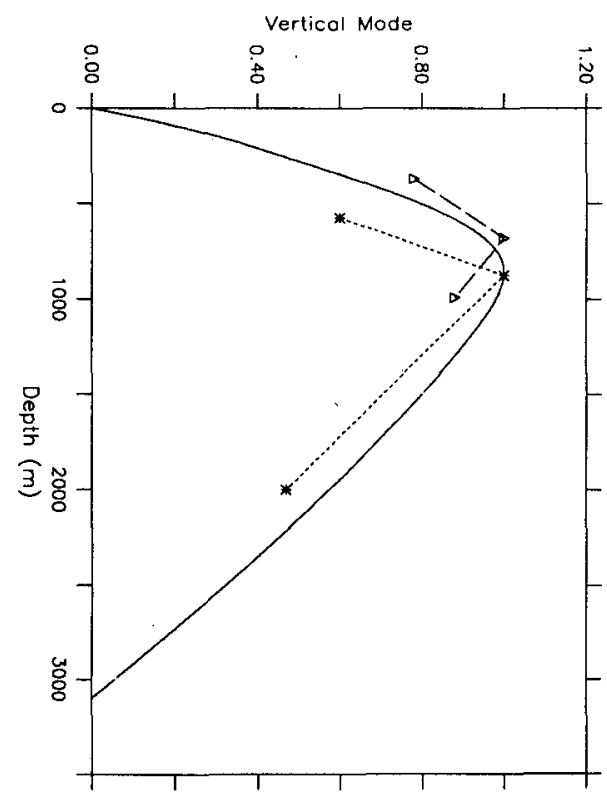

FIG. 2. Shape of the first baroclinic dynamical mode $x_{1}$ (solid line), vertical displacement mode $\dot{\chi}$ from the Cape Hatteras mooring (large dashes), and vertical velocity mode $w$ at $68^{\circ} \mathrm{W}$ from Hall (1986a) (small dashes). The $\dot{\chi}$ and $w$ curves are first mode empirical orthogonal functions; all three curves have been normalized to have maximum value $=1$ clinic mode, so that (2) simplifies to $z^{\prime}(x, y, z, t)$ $\approx A_{1}(x, y, t) \chi_{1}(z)$, and we show how the IES can be used to measure the first mode amplitude $A_{1}(x, y, t)$. The expression for the travel time measured by the IES is

$$
\tau=2 \int_{H}^{0} \frac{d z}{C(T, S, P)},
$$

where $C(T, S, P)=$ sound speed, $z=H$ is the bottom depth, and $z=0$ is the sea-surface ( $z$ is taken to be positive downwards). The perturbed sound speed profile is expressed as

$$
\begin{aligned}
& C(x, y, z, t) \\
& \quad=C\left[T_{0}\left(z+A_{1} \chi_{1}\right), S_{0}\left(z+A_{1} \chi_{1}\right), P(z)\right],
\end{aligned}
$$

(pressure is not perturbed in the integration because it is in essence the integration variable). We define the deviation travel time $\tau^{\prime}$ as the difference from the unperturbed (basic state) travel time,

$$
\tau^{\prime} \equiv \tau-\tau_{0}=2 \int_{H}^{0} \frac{d z}{C(x, y, z, t)}-\int_{H}^{0} \frac{d z}{C_{0}(z)} .
$$

For small perturbations (5) can be written

$$
\begin{aligned}
C(x, y, z, t) \approx C_{0}\left[T_{0}(z),\right. & \left.S_{0}(z), P(z)\right] \\
+\left(\frac{\partial}{\partial T} C_{0} \frac{d}{d z} T_{0}(z)\right. & \left.+\frac{\partial}{\partial S} C_{0} \frac{d}{d z} S_{0}(z)\right) \\
& \times A_{1}(x, y, t) \chi_{1}(z) .
\end{aligned}
$$

Substituting this expression into (6) and using the binomial expansion gives

$$
\tau^{\prime}=\gamma A_{1}(x, y, t),
$$

where the constant proportionality $\gamma$ is equal to

$$
\begin{array}{r}
\gamma=-2 \int_{H}^{0}\left[\frac{\partial}{\partial T} C_{0} \frac{d}{d z} T_{0}(z)+\frac{\partial}{\partial S} C_{0} \frac{d}{d z} S_{0}(z)\right] \\
\dot{\times} \chi_{1}(z) /\left[C_{0}(z)^{2}\right] d z .
\end{array}
$$

Using the basic state profiles of temperature, salinity, and buoyancy frequency and the calculated mode shape $\chi_{1}(z)$, expression (9) can be evaluated numerically. Then the IES measurement gives us $\tau^{\prime}$ and using (8) we determine $A_{1}(x, y, t)$, the amplitude of the first baroclinic mode as a function of time at location $(x, y)$.

While (8) tells us that for small perturbations the travel time should be linearly proportional to the baroclinic mode amplitude, there is no need a priori to make this assumption. We can simply use (6), which can be expressed $\tau^{\prime}=f\left(A_{1}\right)$, to evaluate numerically the simulated travel time for a given disturbance and tabulate the values of $\tau^{\prime}$ for the entire range of possible amplitudes, from which we form the inverse function

$$
A_{\mathrm{l}}(x, y, t)=f^{-1}\left(\tau^{\prime}\right) \text {. }
$$


Expression (10) can then be used to obtain oceanic values of $A_{1}$ by measuring $\tau^{\prime}$ from the IES. Finally we calculate the temperature from $\tau^{\prime}, T(x, y, z, t)$ $\approx T_{0}\left[z+A_{1}(x, y, t) \chi_{1}(z)\right] \approx T_{0}\left[z+f^{-1}\left(\tau^{\prime}\right) \chi_{1}(z)\right]$.

\section{The basic state profile}

\section{a. Averaging scheme}

It is not obvious how to devise a basic state profile for a given location in the Gulf Stream. As seen in Fig. 1 , the $\mathrm{CM}$ mooring site is located at $35^{\circ} 26^{\prime} \mathrm{N}, 73^{\circ} 59^{\prime} \mathrm{W}$ near Cape Hatteras. In August of 1982 Endeavor cruise 88 (EN088) occupied a CTD section across the Gulf Stream near the IES and mooring locations ( see Stalcup et al. 1985); the section is shown in Fig. 1 as well. We used this CTD data to construct two different basic states.

Figure 3 shows the EN088 vertical section of potential temperature in relation to the three IES sites and current meter mooring; we use only the four CTD stations nearest to the instrument locations. For the first basic state profile we computed a Gaussian-weighted average of the four stations, giving stations 49 and 50

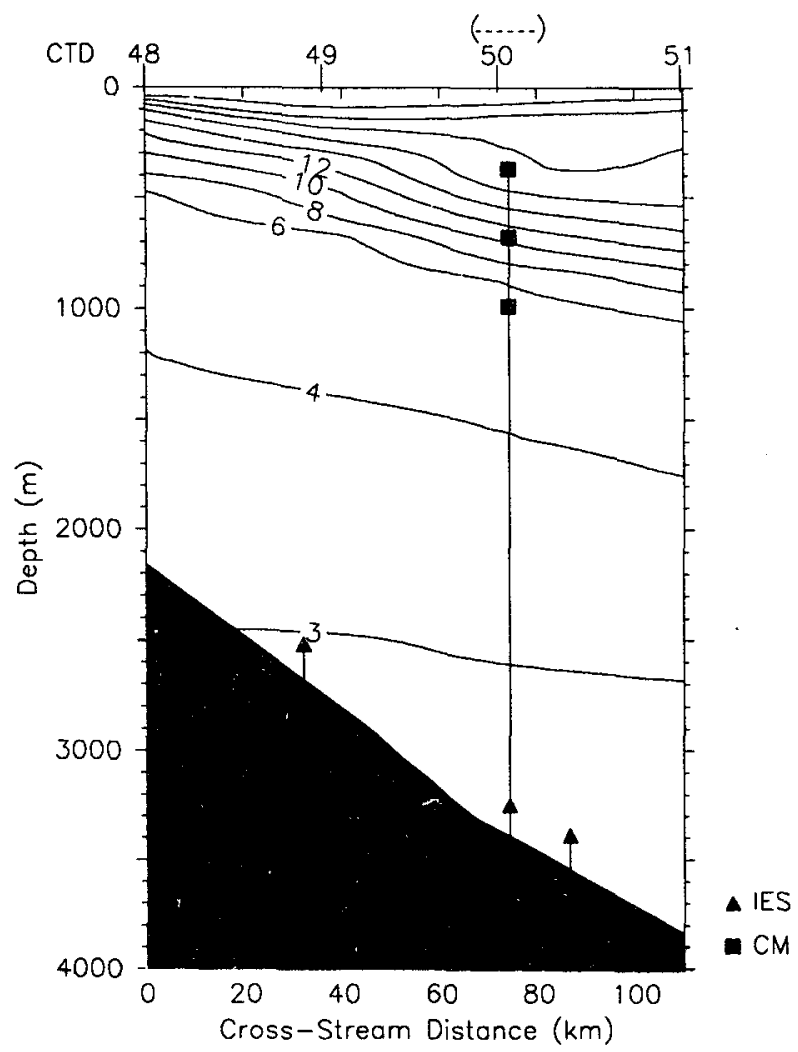

Fig. 3. Vertical section of potential temperature $\left({ }^{\circ} \mathrm{C}\right)$ for the CTD stations in Fig. 1, shown with the locations of the IES's and CM mooring. The standard deviation meander width of the Gulf Stream during the three month moored experiment is indicated at the top of the figure by the parentheses and dashed line around the mooring site. the most weight (the weighting factors are $0.1,0.4,0.4$ and 0.1 for stations $48,49,50$ and 51). We call this the full stream basic state. As will be shown in section 4 the IES-derived mean temperature profile that results from this basic state does not agree very closely with the three CM mean temperatures.

Figure 3 shows that the current meter mooring is located on the anticyclonic side of the Gulf Stream (its $400 \mathrm{~m}$ instrument is in the $18^{\circ} \mathrm{C}$ water). Near Cape Hatteras the Gulf Stream does not meander very far; Fig. 3 shows the standard deviation meander width of the Gulf Stream during the three month duration of the experiment (calculated from the IESs). It seems logical then to include in a basic state average only that portion of the CTD section that meanders past the mooring site. For the mooring in question, this means devising a basic state that includes $18^{\circ} \mathrm{C}$ water. Hence for the second basic state profile we computed a weighted average (explained below) of stations 49,50 and 51; we call this the meander width basic state. Note that contrary to the full stream basic state, which applies to all cross-stream positions, there will be a different meander width basic state for each cross-stream location in the Gulf Stream (to be thought of as a basic state profile that slowly varies with cross-stream distance).

To obtain an optimal comparison of the IES-derived temperatures and CM temperatures, we used the mean $\mathrm{CM}$ temperatures to help determine the meander width basic state. Specifically we used the weighted average of stations 49,50 and 51 that resulted in the best agreement (in the least-squares sense) between the basic state temperatures and $\mathrm{CM}$ mean temperatures at the three instrument depths. This resulted in a mix of 94 percent station 50 and 6 percent station 51 (no contribution from station 49). The corresponding basic state profiles of $T_{0}, d T_{0} / d z$, and $\chi_{1}$ are shown in Fig. 4, compared with the same curves for the full stream basic state (the grid spacing is $10 \mathrm{~m}$ ). Note that the mean CM temperatures (also shown in Fig. 4) are indicative of the meander width $T_{0}$ profile. For those variables which are relatively smooth (such as temperature, salinity, etc.) a single Gaussian filter $e^{-\left(z^{2} / a^{2}\right)}$ was applied to the data with $a=25 \mathrm{~m}$. For quantities that are inherently noisy (such as buoyancy frequency) the Gaussian filter was applied twice. To compute the mode shapes $\chi_{i}(z)$, the vertical structure equation ( 3 ) was solved using a numerical shooting technique (see Rossby 1974). Ideally it would be desirable to use an ensemble average of historical CTD stations to construct the basic state profile; however, the existence of such data near Cape Hatteras is limited. We compared three Pegasus temperature profiles (from Halkin et al. 1985) taken at a nearly identical anticyclonic location in the Gulf Stream at $73^{\circ} \mathrm{W}$ over a three month span and found that the average standard deviation over the main thermocline is less than $0.1^{\circ} \mathrm{C}$. This together with the Gaussian smoothing to remove small scale noise sug- 

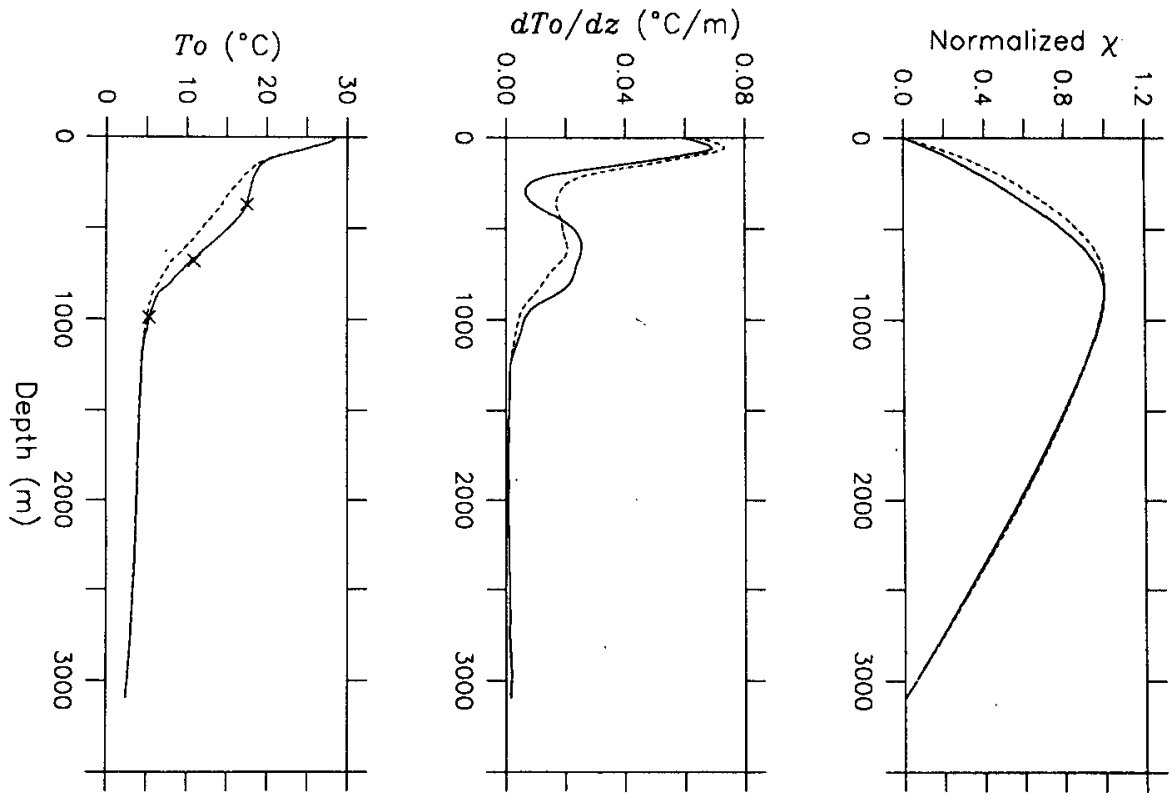

FIG. 4. Basic state profiles of temperature $\left(T_{0}\right)$, vertical temperature gradient $\left(d T_{0} / d z\right)$, and the corresponding first baroclinic mode shape $\left(\chi_{1}\right)$ for the meander width average (solid line) and the full stream average (dashed line). The vertical modes have been normalized to have maximum value $=1$. The mean CM temperatures (crosses) used to construct the meander width average are shown in comparison.

gests that errors involved in using a single CTD section are small.

In regions of the Gulf Stream characterized by pronounced meandering (downstream of Cape Hatteras) a single IES location will at times be in different parts of the Gulf Stream, conceivably alternating between slope water and the Sargasso Sea. It is evident that in this case a single meander width basic state profile is not adequate; in theory a time-varying basic state would have to be employed. Implementing such a scheme, however, would be difficult and is beyond the scope of this investigation.

\section{$b$. Sensitivity of the basic state}

As explained in section 2, once the basic state profiles are determined we then perturb the sound speed as in (5) and compute the dependence of $\tau^{\prime}$ on $A_{1}$ using (6) (ultimately computing the inverse of this). In particular, (6) is evaluated numerically using a finite difference scheme for a range of values of $A_{1}$. Figure 5 graphs $\tau^{\prime}$ vs $A_{1}$ for the meander width basic state. The convention we use is that a positive amplitude corresponds to upward displacement of the isotherms (at a given depth the temperature is colder). The discrete data points in Fig. 5 are obtained using the full nonlinear relation (6), whereas the solid line is the slope given by the small amplitude approximation (8). In Fig. 5a it is seen that $\tau^{\prime}$ starts to deviate slightly from the small amplitude solution for $A_{1} \geqslant 100 \mathrm{~m}$. This should be contrasted against Fig. $5 \mathrm{~b}$, which plots the same quan- tities for $A_{2}$ (amplitude of the second baroclinic mode). In this case the small amplitude approximation quickly becomes invalid, and can even indicate the wrong sense.
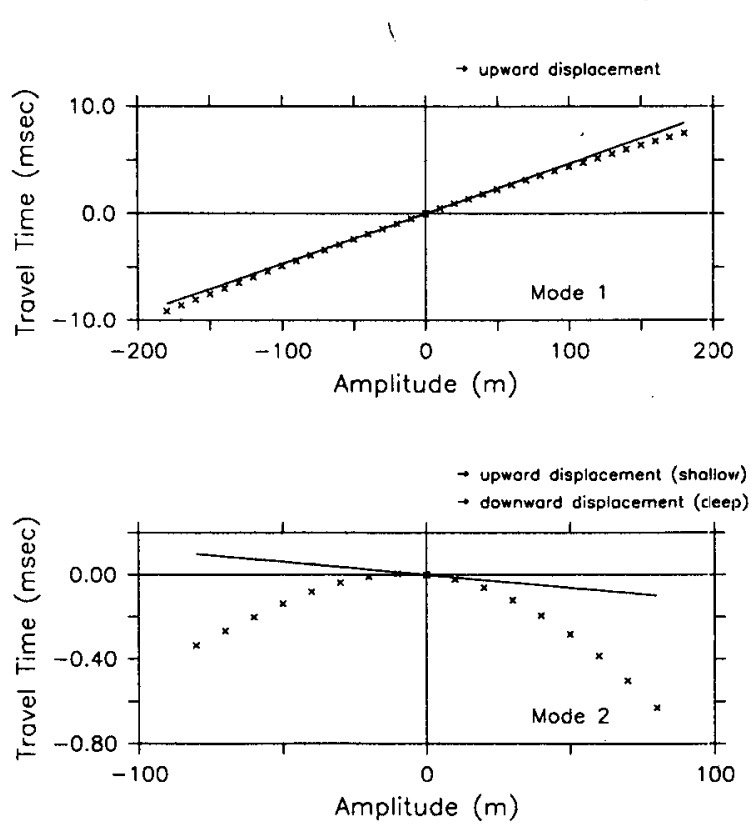

FIG. 5. Dependence of deviation travel time on the amplitude of the (a) first and (b) second baroclinic mode. The figure graphs both the full nonlinear relationship (6) (discrete data points) and the small amplitude approximation ( 8 ) (solid line). 
In line with the previous discussion concerning the insensitivity of $\tau$ to second mode perturbations at midlatitudes, note the difference in travel time scales used in Figs. 5a and 5b. For a perturbation of $25 \mathrm{~m}, \tau$ is 20 times more sensitive to a first mode disturbance than a second mode disturbance at this location in the Gulf Stream. Note that this does not say that individual isotherms are not affected as much by mode 2 , as in fact they are; it is just that the IES is not an appropriate instrument to measure second mode variability in the Gulf Stream.

In addition to the arguments given above for using a meander width basic state profile instead of a full stream profile, there exists another reason as well. At the cross-stream location of the CM mooring the resulting first mode amplitudes $\left(A_{1}\right)$ corresponding to the full stream profile will in general be much larger than those for the meander width profile. This is simply because the full stream basic state isotherms need to be displaced a greater vertical distance to obtain temperatures indicative of the anticyclonic side of the Gulf Stream (Fig. 4a). Not only does this mean the amplitudes will be outside the linear regime, but it could lead to false inversions (e.g., when a warmer isotherm is displaced downward beyond a colder isotherm). This invalid state will occur when $\left|d / d z\left[A_{i} \chi_{i}(z)\right]\right| \geqslant 1$, and for $\chi_{1}$ this happens when $A_{1} \geqslant 400 \mathrm{~m}$ (as opposed to $\chi_{2}$, for which $A_{2}$ need only be $\geqslant 80 \mathrm{~m}$ for this to occur).

Figure 4 shows that while the profiles of $T_{0}(z)$ and $d T_{0}(z) / d z$ differ quite markedly for the meander width basic state vs the full stream basic state, the corresponding $\chi_{1}(z)$ profiles show little difference. Since $N_{0}(z)$ is used only to compute the mode shape, this suggests that it is probably not crucial that we use a meander width $N_{0}(z)$ profile, but rather, a canonical Gulf Stream $N(z)$ profile might suffice. Also, since the sound speed is much more sensitive to variations in temperature than salinity, the same might also be true of the basic state salinity $S_{0}(z)$. To test this we computed the values of $\tau^{\prime}$ vs $A_{1}$ from (6) using the meander width temperature profile $T_{0}(z)$, but replacing the profiles of salt and buoyancy frequency with canonical Gulf Stream profiles of $S_{0}(z)$ and $N_{0}(z)$ respectively. The resulting deviation travel times are hardly distinguishable from those in Fig. 5a. This result has the potentially useful consequence that density data per se are not needed near the IES sites, only a temperature section is required, such as an easily obtained section of deep XBT casts.

\section{IES-derived temperature}

\section{a. Time series}

Once the inverse function (10) is computed for a given IES location, in order to apply it we need to convert the travel time $(\tau)$ of the IES into deviation travel time $\left(\tau^{\prime}\right)$ defined by (6). Since $\tau$ varies only on the order of $10 \mathrm{~m} \mathrm{~s}^{-1}$ or so for typical vertical displacements in the Gulf Stream near Cape Hatteras, it is not accurate enough to directly compute the reference travel time $\tau_{0}$ by evaluating the integral of $C_{0}(z)^{-1}$ [i.e., the last term on the right hand side of (6)]. This is because we don't know the value of the sea surface height accurately enough. We can instead use the mean $\mathrm{CM}$ temperatures to calibrate the travel time. This was done by determining the $\tau_{0}$ that gives the best agreement between the resulting IES-derived mean temperatures and $\mathrm{CM}$ mean temperatures at the three instrument depths. In particular this meant finding the $\tau_{0}$ that minimized the expression $\sum_{i=1}^{3}$ $\left(\overline{T\left(z_{i}+A_{1}\left(\tau-\tau_{0}\right) \chi_{1}\left(z_{i}\right)\right)}-\overline{T_{\mathrm{cm}}}\right)^{2}$, where the sum is over the current meters.

The relation (10) was then used to determine $A_{1}(t)$ at the mooring site, then $A_{1}(t) \chi_{1}(z)$ was used to perturb the basic state temperature, finally obtaining a timevarying vertical profile of temperature. Figure 6 a shows the three month mean profile (solid line) compared to the mean current meter temperatures, displaying good agreement. Figure $6 \mathrm{~b}$ is the same plot for the standard deviations; while the IES slightly underestimates the CM standard deviations (probably due to the undetected presence of higher mode variability), the trend is consistent with the small shallow values due to the $18^{\circ} \mathrm{C}$ water. Also shown in Fig. $6 \mathrm{a}$ is the resulting mean IES temperature profile if instead the full stream basic

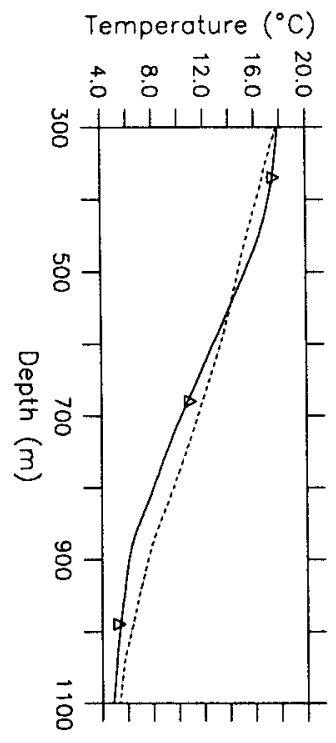

(a)

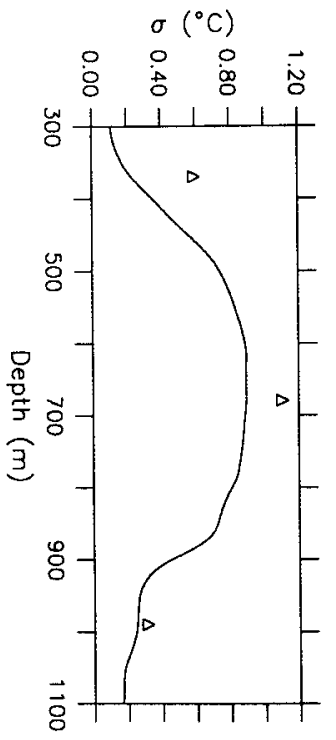

(b)
FIG. 6. (a) Mean vertical profile of IES-derived temperature using the meander width basic state (solid curve) shown in relation to the measured CM mean temperatures (triangles). Also shown is the mean profile using the full stream basic state (dashed curve) which is unable to match the observed CM values. (b) Standard deviation profile of IES-derived temperature (meander width basic state) compared to the $\mathrm{CM}$ values. 
state temperature profile is used (dashed line). This profile is clearly inadequate in predicting the observed current meter mean temperatures.

Figure 7 compares the individual current meter temperature time series to those derived from the IES. The current meter temperature data were corrected for mooring motion using a temperature dependent value of $d T / d z$ determined from the basic state CTD profile. This together with a time series of pressure was used to correct the temperatures to common depths of 370 $\mathrm{m}, 680 \mathrm{~m}$, and $990 \mathrm{~m}$ following the procedure in Hogg (1986). Only the uppermost current meter contained a pressure sensor; for the deeper instruments a pressure time series was derived using the predicted relative mooring motion according to Mo and Watts (1987).

Figure 7 shows that the IES captures most of the variability displayed in the individual current meter temperature records. Like the current meter, the IES signal at $370 \mathrm{~m}$ has a different character due to the $18^{\circ} \mathrm{C}$ water. The value of the correlation coefficients for the CM and IES (listed to the right of each plot) are relatively high at each level, though smallest at 1000 $\mathrm{m}$. It is interesting to note that the raw travel time record (not shown) of the IES is most correlated with the CM temperature at $680 \mathrm{~m}$, but the IES-derived temperature is most correlated with the CM temper-
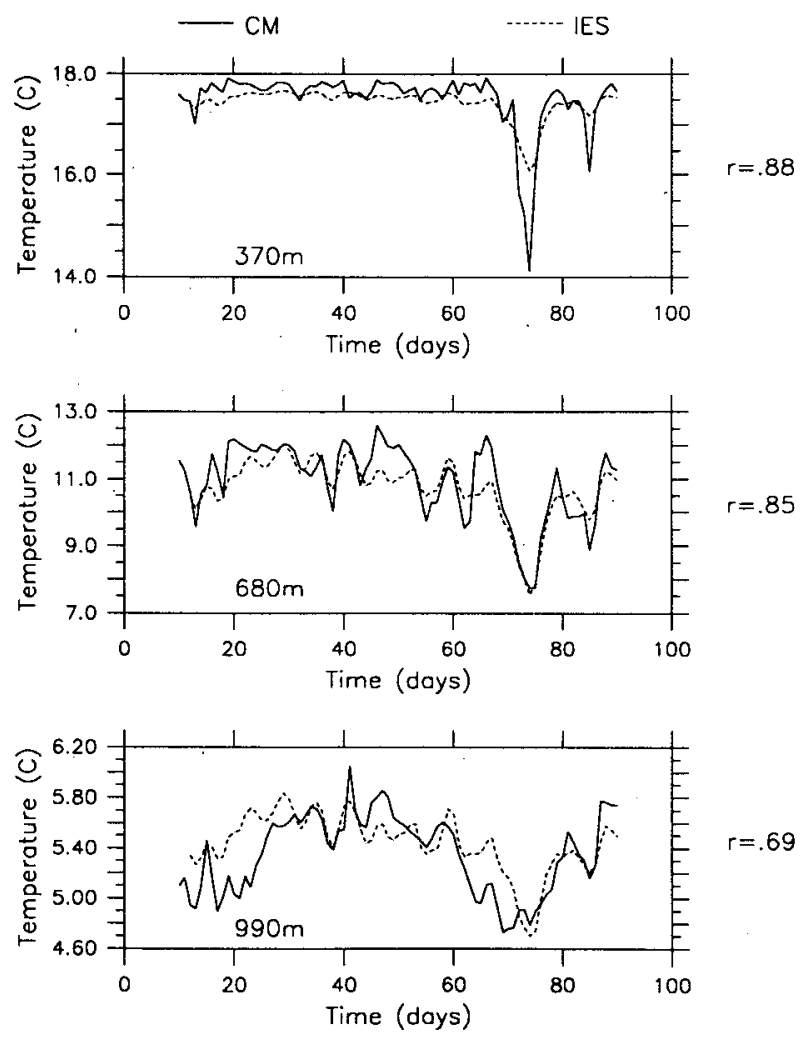

FIG. 7. Comparison of the IES-derived temperature time series to the $\mathrm{CM}$ time series at the three instrument depths. The correlation coefficients are shown on the right.
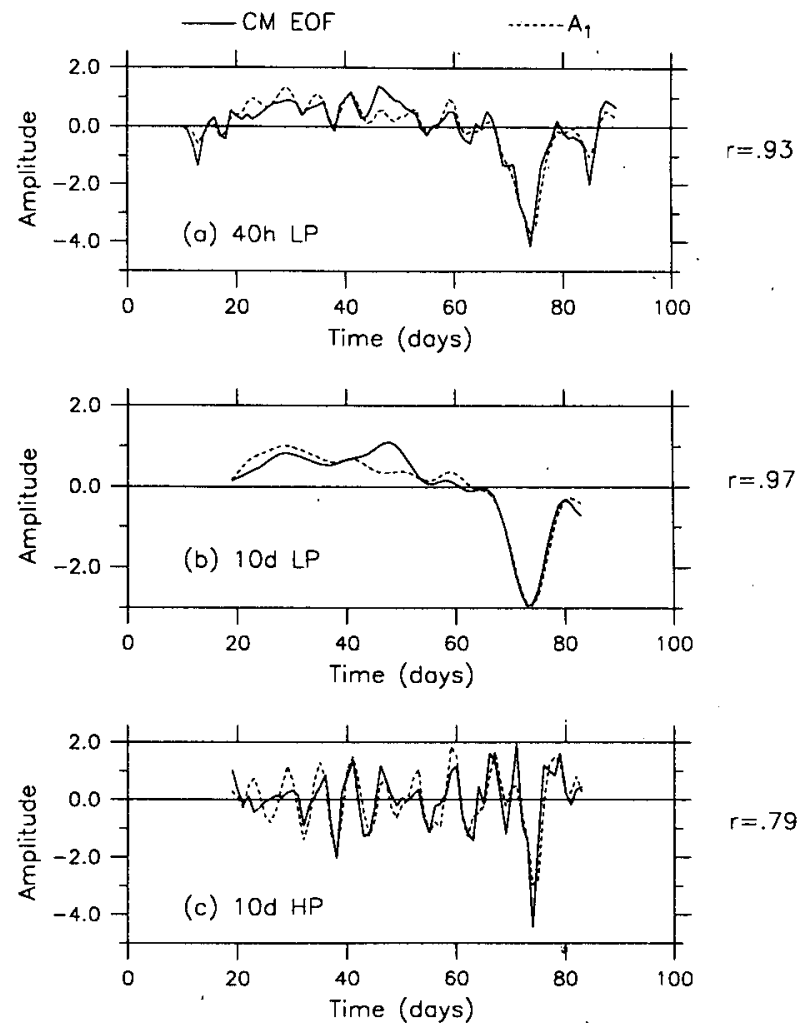

FIG. 8. Time series of the first baroclinic mode amplitude from the IES compared to the first EOF temperature mode tirne series from the three CMs. Both curves have zero mean and have been normalized to a standard deviation of unity. The correlation coefficients are also shown. (a) $40 \mathrm{~h}$ low passed. (b) 10 day low passed. (c) 10 day high passed.

ature at $370 \mathrm{~m}$ (Fig. 7). This is because the small nonlinearity in conversion to temperature is greatest at 370 $\mathrm{m}$ (due to the transition into $18^{\circ} \mathrm{C}$ water), and this improves the correlation for temperature at this level. This effect is slight however, and the small amplitude approximation (8) gives accurate solutions (not shown ).

\section{b. Empirical temperature modes}

To extract the dominant temperature variability in the current meter records, an empirical orthogonal function (EOF) analysis was done. The eigenfunctions and eigenvalues were computed for the CM temperature correlation matrix (thereby giving equal weight to each of the temperature records). The resulting, EOFs were then redimensionalized by the CM standard deviations. The first EOF mode accounts for 71 percent of the CM temperature variance; its amplitude time series is shown in Fig. 8 (solid line) and its vertical structure in Fig. 9a (dashed line). The EOF time series is compared with the $A_{\mathrm{l}}$ amplitude time series of the first baroclinic dynamical mode from the IES (both curves have zero mean and unit standard deviation to 
allow for a better comparison). The two $40 \mathrm{~h}$ lowpassed curves (Fig. 8a) show a high correlation ( $r$ $=0.93$ ), clearly demonstrating that the dominant temperature variability at this location in the Gulf Stream can be modeled as first baroclinic mode (and is effectively measured by the IES). Figures $8 \mathrm{~b}$ and $8 \mathrm{c}$ show the same comparison for periods longer than and shorter than 10 days respectively. While the correlation is highest for long periods, the agreement is striking at shorter periods as well.

This result shows that the first EOF temperature mode can be accurately regarded as a first baroclinic mode; however, the same is not true of the respective second modes. This is demonstrated in Fig. 9, which plots the vertical profiles of $\Delta T$ associated with the first two baroclinic modes, compared with the vertical structure of the first two empirical temperature modes. It is seen that while the first baroclinic mode $\Delta T$ profile corresponds nicely to the first EOF temperature mode (Fig. 9a), the isotherm displacements of a second dynamical mode are inconsistent with that observed in the second EOF mode (Fig. 9b).

\section{c. Calibration using XBTS}

In the preceding calculation we made use of the current meter temperature data to help derive the IES
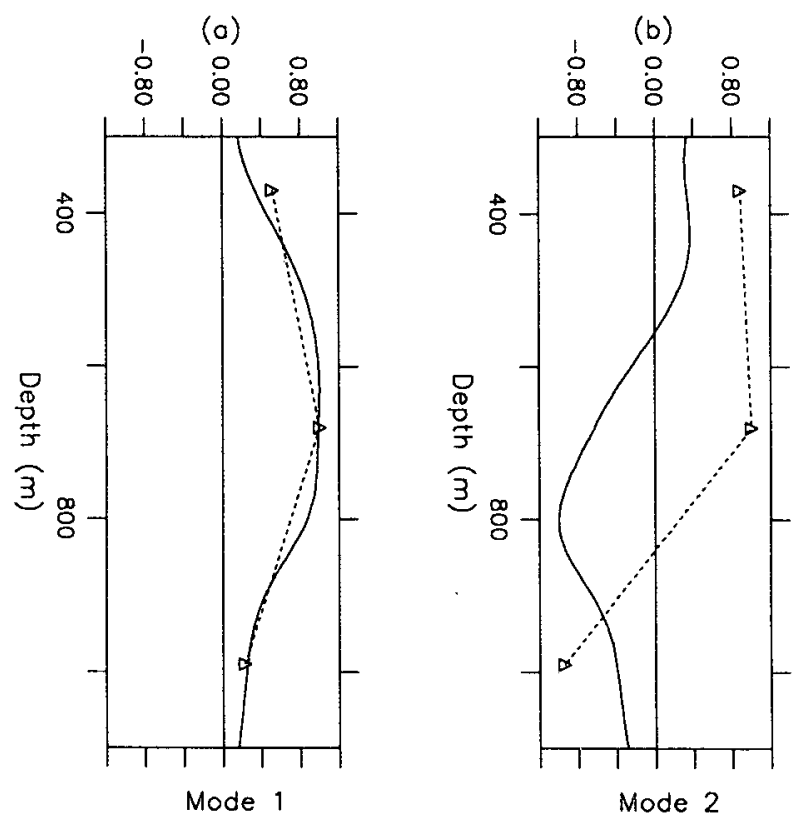

FIG. 9. (a) Vertical profile of temperature change, $\Delta T$, for a first baroclinic mode displacement of $50 \mathrm{~m}$ (solid line), shown in relation to the vertical structure of the first $\mathrm{CM}$ temperature EOF mode. $\Delta T$ is the difference between the perturbed and unperturbed (basic state) temperature; it has been smoothed with a Gaussian filter $e^{-\left(z^{2} / a^{2}\right)}$, with $a=25 \mathrm{~m}$. Both curves have been normalized to have maximum value $=1$. (b) Same plot for a second baroclinic mode displacement of $5 \mathrm{~m}$ and the second EOF temperature mode (the shapes of the $\Delta T$ curves are insensitive to the value of the mode displacement chosen).
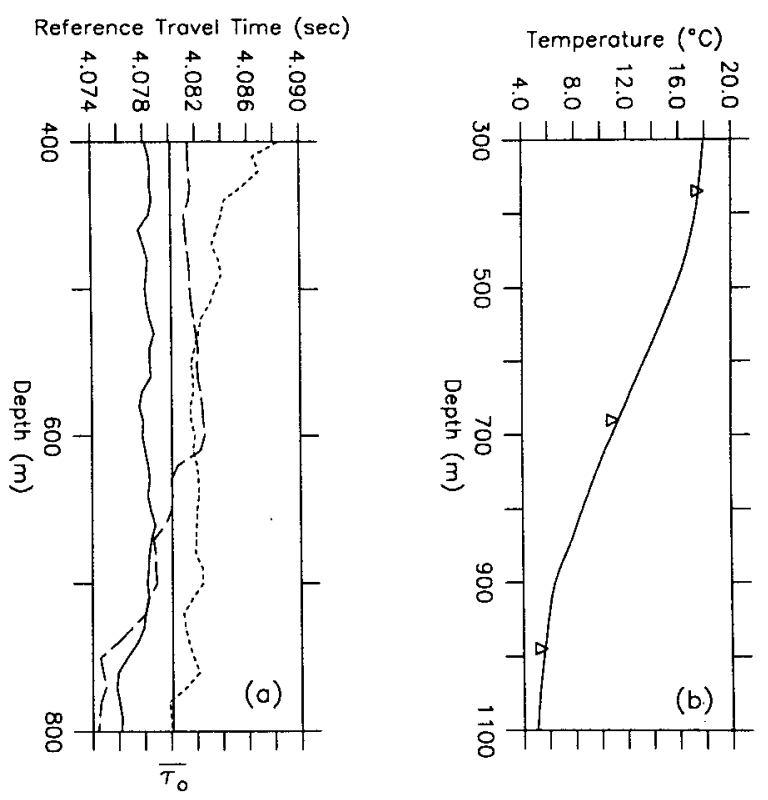

FIG. 10. (a) Vertical profiles of reference travel time $\left(\tau_{0}\right)$ obtained by matching the IES temperature to the observed XBT temperature at each depth, for the three XBT casts taken at the IES site. The average reference travel time $\overline{\tau_{0}}$ (solid line) was obtained by first computing the mean vertical profile of $\tau_{0}$, then taking its vertical average weighted by the inverse of the scatter at each depth. Depths shallower than $400 \mathrm{~m}$ were not used because of the large noise in $\tau_{0}$. (b) Mean IES temperature profile using the reference travel time from (a), compared to the mean CM temperatures (to be compared to Fig. 6a).

temperature profile. The true value of using the IES to measure Gulf Stream temperature obviously comes from using the IES alone, not in conjunction with moored data. The CM data were used above both to determine the basic state average and to calibrate $\tau_{0}$ for the IES travel time. Both of these steps can be accomplished by alternate (though slightly less precise) means. The basic state profile is not overly sensitive to the exact mix of CTD stations used to form it; the mix can be adequately determined by inspection of Fig. 3 and taking into account the rms Gulf Stream meander width. Regarding the IES calibration, this can be done using in situ XBT data.

At the CM mooring/IES site there were three XBT profiles taken at different times during the deployment and recovery cruises. By matching the IES-derived temperature profile to the observed XBT profile, a value of the reference travel time $\tau_{0}$ is obtained at each depth (for each XBT). The resulting $\tau_{0}$ profiles are shown in Fig. 10a; the quantity $\overline{\tau_{0}}$ is the vertical average of the three curves weighted by the inverse of the scatter at each depth. The value of $\overline{\tau_{0}}$ is $4.080 \mathrm{~s}$, compared with $4.079 \mathrm{~s}$ obtained from the CM calibration. Figure $10 \mathrm{~b}$ shows the mean IES-derived temperature profile using this value of the reference travel time; it is slightly warmer than the same curve in Fig. 6a, which uses the 
$\mathrm{CM}$ calibration (warmer by $0.4^{\circ} \mathrm{C}$ in the thermocline, $0.2^{\circ} \mathrm{C}$ at $1000 \mathrm{~m}$ ).

\section{IES-derived geostrophic velocity}

In this section we construct a time-varying vertical profile of alongstream geostrophic velocity at the $\mathrm{CM}$ mooring site, using the travel time records from the three IESs surrounding the mooring (Fig. 1). This result is anticipated after viewing the success in determining $T(z, t)$ using the IES; it is then a matter of determining the cross-stream temperature gradient $\partial T /$ $\partial x$ and applying the thermal wind balance. The simplest calculation would be to compute the temperature profiles at two IESs that bracket the desired location, then apply simple finite-differencing. Because of the large distance between the inshore and offshore IESs, however, the errors accompanying such a finite-difference would be too large. Instead we use a polynomial fit which uses the data from all three IESs.

The first step is to devise the appopriate (meander width) basic state profiles for each IES site, which was done by using Fig. 3 to determine the mix of CTD stations to use. Next the inverse function (10) (as in Fig. 5a) was computed at each site, and finally the corresponding reference travel time $\tau_{0}$ was determined using the XBT calibration process described above. The CTD basic state data were used to compute a basic state profile of dynamic height at each site (relative to the surface) $D_{0}(z)=\int_{0}^{p} \delta_{0} d p$, where $\delta_{0}=$ specific volume anomaly of the basic state. Then a time-varying profile of dynamic height was obtained in similar fashion to the temperature profile above, $D(z, t)=D_{0}[z$ $\left.+A_{1}(t) \chi_{1}(z)\right]$. To obtain the relative geostrophic velocity,

$$
\left(u(z)-u_{r}\right)=-\frac{10}{f} \frac{\partial}{\partial x} D(x, z, t),
$$

where $u_{r}$ is the reference velocity, we compute $\partial D / \partial x$ as follows. At each point in time and at each depth the second order polynomial, which passes through the three values of $D$ at the three sites, is computed; the time averaged polynomials at the three $\mathrm{CM}$ depths are shown in Fig. 11. The derivative is then evaluated at the mooring site. Of course, the reference velocity $u_{r}$ has to be determined by an independent direct measurement at some level. We matched the mean IESderived velocity at $370 \mathrm{~m}$ to the mean alongstream (i.e., perpendicular to the IES line) CM velocity at 370 $\mathrm{m}$. Figure 12a shows the resulting mean IES geostrophic profile in relation to the individual $\mathrm{CM}$ means (the $990 \mathrm{~m} \mathrm{CM}$ velocity record contained a gap of more than half the record length, so all comparisons to the $\mathrm{CM}$ data involve only the upper two levels of $370 \mathrm{~m}$ and $680 \mathrm{~m}$ ). The thing to note about Fig. 12a is the complete agreement between the IES and CM velocities at $680 \mathrm{~m}$, i.e. the vertical shear of the IES-derived profile is consistent with that observed by the two current me-
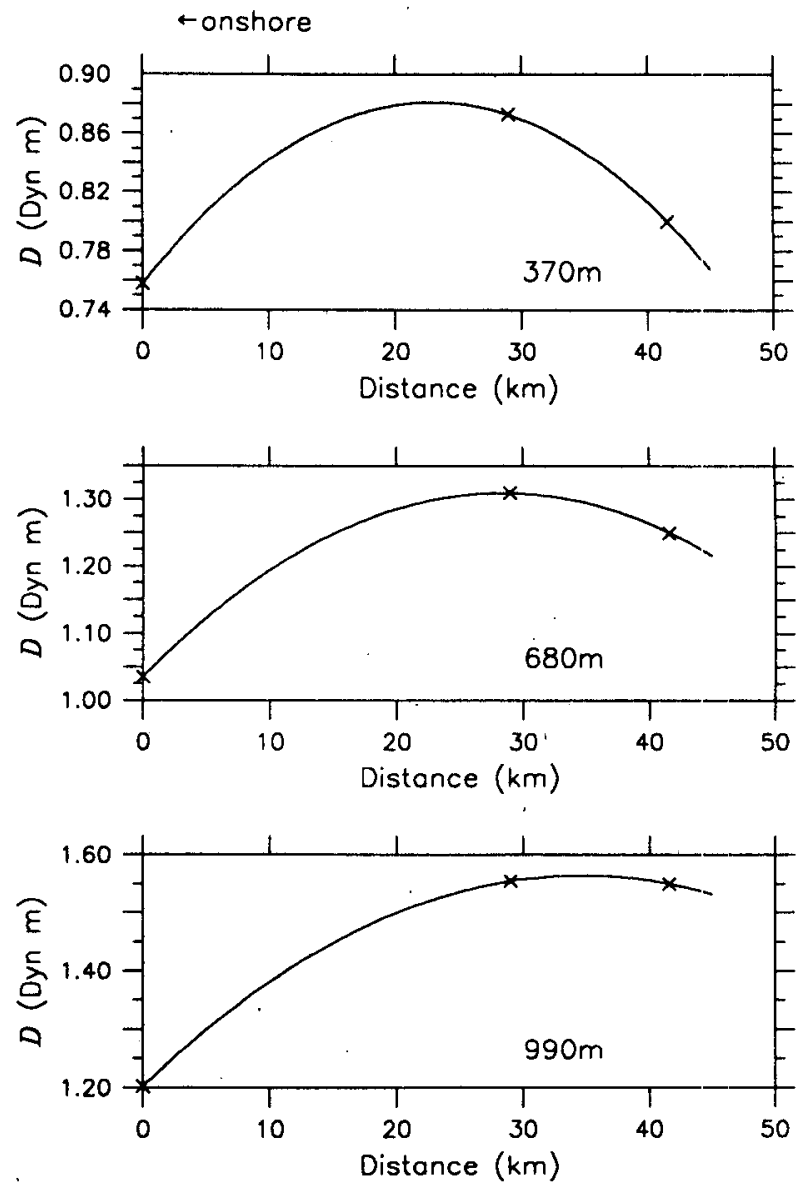

FIG. 11. Mean values of IES-derived dynamic height (relative to the surface) at the depths of the three CMs, for the three crosis-stream IESs. The data points are the IES values, and the curves are the interpolating polynomials used to compute $\partial D / \partial x$. The difference in sign of the polynomial slopes between the shallower levels and the deepest level at the central IES site reflects the southward tilt of the Gulf Stream velocity core with depth.

ters. For the standard deviations (Fig. 12b), the IES gives a much better measure at $370 \mathrm{~m}$ than at $680 \mathrm{~m}$.

The individual time series at the CM depths are shown in Fig. 13 along with the correlation coefficients. As was the case with temperature, the IES reproduces much of the velocity variability observed by the current meters (again the agreement is best at the shallowest level). Figure 14 shows that the IES captures the dominant variability exhibited by the first EOF velocity mode. Note in Fig. 14 that the biggest discrepancy between the IES and CM occurs between days 64 and 77. It is precisely during this time that the $370 \mathrm{~m}$ and $680 \mathrm{~m}$ velocity records display the biggest difference in character, the velocity at $370 \mathrm{~m}$ being mostly out of phase with the velocity at $680 \mathrm{~m}$ (see Fig. 13). This corresponds to a higher mode vertical structure and will not be adequately detected by the IES.

Satellite maps show that during this time period a warm core ring was interacting with the Gulf Stream 


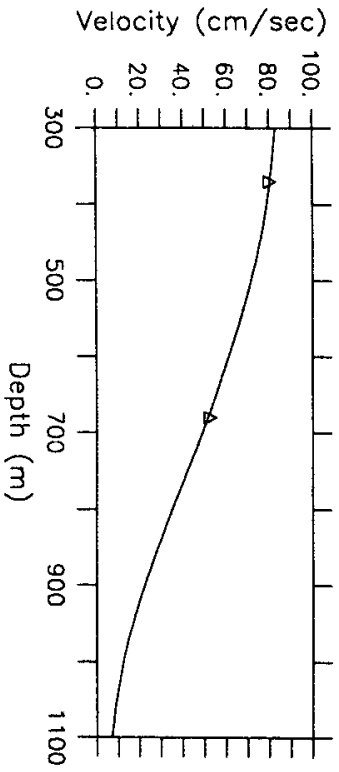

(a)

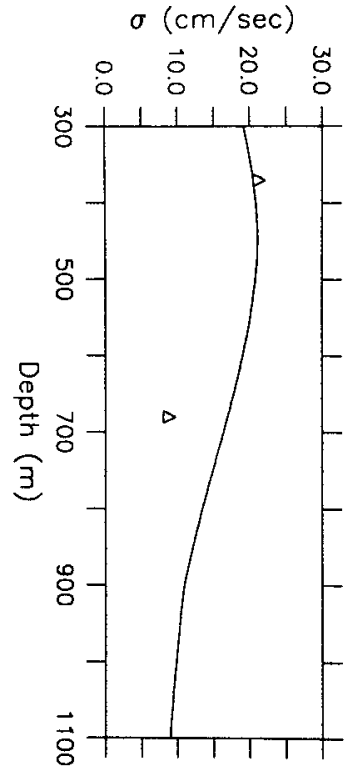

(b)
FIG. 12. (a) Mean vertical profile of geostrophic velocity derived from the IES (solid line), compared to the measured mean CM downstream velocities (triangles). The geostrophic profile has been referenced using the $\mathrm{CM}$ mean at $370 \mathrm{~m}$. Interestingly, the same geostrophic profile would have resulted had we referenced it to zero velocity at $1500-2000 \mathrm{~m}$ (although this may not be a general result). (b) Same as panel (a) for the standard deviations.

a bit downstream of this location. Kontoyiannis (1988) has shown that during Gulf Stream/ring interactions ageostrophic velocities can be significantly large, at times as much as 50 percent of the total velocity. It is
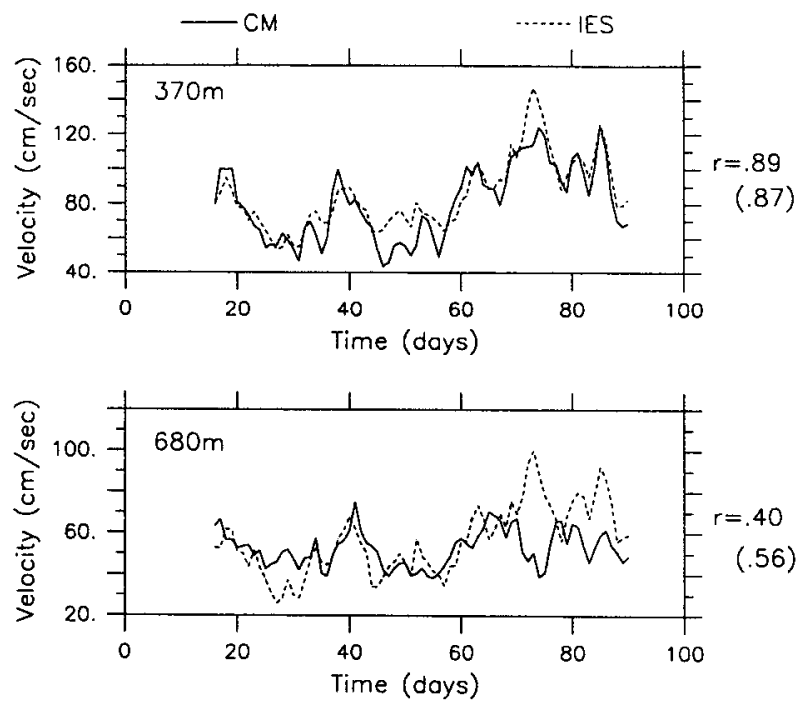

FIG. 13. Time series of IES-derived geostrophic velocity compared to the $\mathrm{CM}$ time series of alongstream velocity at $370 \mathrm{~m}$ and $680 \mathrm{~m}$. The correlation coefficients are shown on the right; the numbers in parentheses are the values when the warm core ring event (days 65 80 ) is omitted.

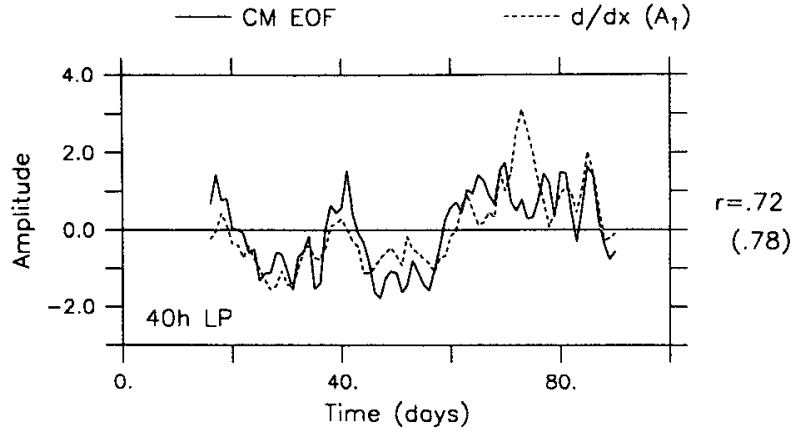

FIG. 14. Time series of the cross-stream derivative of IES first baroclinic mode amplitude, compared to the first EOF velocity mode time series for the upper two $\mathrm{CM}$ records. Both curves have been normalized for comparison as in Fig. 8. The baroclinic mode derivative was computed using the interpolating polynomial described in section 5 .

not surprising then to see the disagreement in Fig. 14 between the calculated IES-derived geostrophic velocity and the observed $\mathrm{CM}$ velocity during this time period. When the warm core ring event is omitted from the records the resulting IES-CM correlation at $680 \mathrm{~m}$ is increased (shown in parentheses in Fig. 13). It should be noted that the temperature signature of the warm core ring event ( a pronounced dip during this time period) was accurately detected by the IES (Fig. 8a).

Using concurrent Pegasus velocity data and CTD data at $73^{\circ} \mathrm{W}$, Johns et al. (1988) have shown that observed currents in the core of the Gulf Stream are geostrophic to within 10-15 percent. They further showed that most of the disagreement is due to centripetal acceleration, and that using gradient wind velocities results in even better agreement. It is worth noting that IESs placed alongstream can effectively measure the curvature of the Gulf Stream, so that a carefully spaced array of IESs could be used to calculate vertical profiles of first mode gradient wind velocities in a manner similar to that employed above. Regarding the reference level question, one might envision the use of bottom current meters to provide a reference velocity. In a region with strong bottom trapped dynamics (such as the deep western boundary current near Cape Hatteras) this would not work; however, upstream of Cape Hatteras in the Florida Current bottom current meters would be useful for this purpose.

\section{Summary}

It has been shown that the inverted echo sounder can be used to measure the time dependent amplitude of the first baroclinic dynamical mode. The relationship between travel time and mode amplitude is nearly linear for small amplitude disturbances, though computationally there is no need to make this assumption. A time series of first mode amplitude from an IES in the Gulf Stream near Cape Hatteras was used to perturb a basic state profile of temperature, created from his- 
torical CTD data, to obtain a time-varying vertical profile of temperature. Using several IESs the horizontal temperature gradient was also computed, and using the thermal wind relation a profile of relative geostrophic velocity was obtained. XBT profiles taken at the IES sites were used to calibrate the instruments.

A comparison to current meter measurements shows that the IES accurately measures the dominant variability in both temperature and alongstream velocity observed in the CM data (the exception being a complicated warm core ring-Gulf Stream interaction in which the IES could not fully resolve the vertical velocity structure). The highest correlation between the IES and CM occurs at long periods, but the agreement is good as well for periods as short as several days. The methodology presented here is feasible only in regions of small Gulf Stream meandering, but its effectiveness near Cape Hatteras demonstrates that such small amplitude disturbances can be modelled effectively as first baroclinic mode fluctuations, and that the IES is an effective and inexpensive way to monitor such variability.

Acknowledgments. The authors wish to thank Karen Tracey, John Bane, and Bill Johns for their help in processing the data as well as their input regarding its application. Terry Joyce kindly allowed us the use of the CTD data. This work was funded by Contract N00014-87-K-0235 of the Office of Naval Research.

\section{REFERENCES}

Chiswell, S. M., D. R. Watts and M. Wimbush, 1986: Using inverted echo sounders to measure dynamic height in the eastern equatorial Pacific during the 1982-1983 El Nino. Deep-Sea Res., 33, 981-991.

Garzoli, S., and E. J. Katz, 1981: Observations of inertia-gravity waves in the Atlantic from inverted echo sounders during FGGE, $J$. Phys. Oceanogr., 11, 1463-1473.

- , and A. Bianchi, 1987: Time-space variability of the local dy- namics of the Malvinas-Brazil confluence as revealed by inverted echo sounders. J. Geophys. Res., 92, 1914-1922.

Halkin, D., T. A. Rago and T. Rossby, 1985: Data report of the PEGASUS program at $73^{\circ} \mathrm{W}$. Technical Report Ref. No. 85-2. [Available from University of Rhode Island Graduate School of Oceanography, Narragansett, RI.]

Hall, M. M., 1986a: Horizontal and vertical structure of the Gulf Stream velocity field at $68^{\circ} \mathrm{W}$. J. Phys. Oceanogr., 16, 18141828 .

- 1986b: Assessing the energetics and dynamics of the Gulf Stream at $68^{\circ} \mathrm{W}$ from moored current measurements. J. Mar. Res., 44, 423-443.

Hogg, N. G., 1986: On the correction of temperature and velocity time series for mooring motion. J. Atmos. Oceanic Technol., 3, 204-214.

Johns, E., D. R. Watts and H. T. Rossby, 1989: A test of geostrophy in the Gulf Stream. J. Geophys. Res., 94, 3211-3222.

Katz, E. J., 1987: Seasonal response of the sea surface to the wind in the equatorial Atlantic, J. Geophys. Res., 92, 1885-1893.

Kontoyiannis, H., 1988: The role of the pressure field in the dynamics and energetics of the Gulf Stream at $73^{\circ} \mathrm{W}$. Masters thesis, University of Rhode Island Graduate School of Oceanography, Narragansett.

Miller, L., D. R. Watts and M. Wimbush, 1985: Oscillations of dynamic topography in the eastern equatorial Pacific. J. Phys. Oceanogr., 15, 1759-1770.

Mo, A., and D. R. Watts, 1987: A computer program for the design of taut subsurface moorings. Technical report number 87-7. [Available from Graduate School of Oceanography, University of RI, Narragansett, RI.]

Rossby, T., 1974: Studies of the vertical structure of horizontal currents near Bermuda. J. Geophys. Res., 79, 1781-1791.

Rossby, H. T., 1987: On the energetics of the Gulf Stream at $73^{\circ} \mathrm{W}$. J. Mar. Res., 45, 59-82.

Stalcup, M. C., T. M. Joyce, R. L. Barbour and J. A. Dunworth, 1985: Hydrographic data from warm core ring 82-B. Woods Hole Oceanographic Institution Technical Report, WHOI-8529 ,

Watts, D. R., and H. T. Rossby, 1977: Measuring dynamic heights with inverted echo sounders: Results from MODE. $J$. Phys. Oceanogr., 7, 345-358.

on propagation and growth. J. Geophys. Res., 87, 9467-9476.

- K. J. Tracey and A. I. Friedlander, 1989: Producing accurate maps of the Gulf Stream thermal front using objective analysis. J. Geophys. Res., 